\title{
Article \\ COPD Guidelines in the Asia-Pacific Regions: Similarities and Differences
}

\author{
Shih-Lung Cheng ${ }^{1,2, *}$ and Ching-Hsiung Lin ${ }^{3,4,5}$ D \\ 1 Department of Internal Medicine, Far Eastern Memorial Hospital, Taipei 22060, Taiwan \\ 2 Department of Chemical Engineering and Materials Science, Yuan Ze University, Zhongli District, \\ Taoyuan 320315, Taiwan \\ 3 Division of Chest Medicine, Department of Internal Medicine, Changhua Christian Hospital, \\ Changhua 50006, Taiwan; teddy@cch.org.tw \\ 4 Institute of Genomics and Bioinformatics, National Chung Hsing University, Taichung 40227, Taiwan \\ 5 Department of Recreation and Holistic Wellness, MingDao University, Changhua 50006, Taiwan \\ * Correspondence: shihlungcheng@gmail.com; Tel.: +886-2-8966-7000 (ext. 2160); Fax: +886-2-7738-0708
}

check for

updates

Citation: Cheng, S.-L.; Lin, C.-H. COPD Guidelines in the Asia-Pacific Regions: Similarities and Differences. Diagnostics 2021, 11, 1153. https:// doi.org/10.3390/diagnostics11071153

Academic Editor: Koichi Nishimura

Received: 1 June 2021

Accepted: 21 June 2021

Published: 24 June 2021

Publisher's Note: MDPI stays neutral with regard to jurisdictional claims in published maps and institutional affiliations.

\begin{abstract}
Chronic obstructive pulmonary disease (COPD) is a preventable and treatable disease that is associated with significant morbidity and mortality, giving rise to an enormous social and economic burden. The Global Strategy for the Diagnosis, Management and Prevention of Chronic Obstructive Pulmonary Disease (GOLD) report is one of the most frequently used documents for managing COPD patients worldwide. A survey was conducted across country-level members of AsiaPacific Society of Respiratory (APSR) for collecting an updated version of local COPD guidelines, which were implemented in each country. This is the first report to summarize the similarities and differences among the COPD guidelines across the Asia-Pacific region. The degree of airflow limitation, assessment of COPD severity, management, and pharmacologic therapy of stable COPD will be reviewed in this report.
\end{abstract}

Keywords: COPD guideline; Asia

\section{Introduction}

Although chronic obstructive pulmonary disease (COPD) is a preventable and treatable disease, it is associated with significant morbidity and mortality, giving rise to an enormous social and economic burden. The results from the Epidemiology and Impact of COPD (EPIC) Asia population-based survey suggest a high prevalence of COPD in the participating Asia-Pacific territories [1] and indicate a substantial socioeconomic burden of the disease in this region. Individuals with the disease reported substantial limitations in their daily activities and loss in work productivity. To address this situation and influence the behavior of healthcare providers and health policy makers and payers, numerous organizations have developed clinical practice guidelines (CPG) to assist in the diagnosis and treatment of COPD. In such an environment, CPG development often relies upon expert opinion. Conflicting interpretations of the literature regarding COPD management may result in disparities across guidelines. Local factors, such as the availability of certain health care services or the cost impact of an intervention, may also influence how local experts view and apply the published literature during guideline development.

The Global Strategy for the Diagnosis, Management and Prevention of Chronic Obstructive Pulmonary Disease (GOLD) report is one of the most frequently used documents for managing COPD patients worldwide [2,3]. It was developed by using an evidencebased methodology and expert opinion consensus and is considered the most up-to-date, comprehensive reference for COPD diagnosis and management. However, a major gap is that its focus is only in the application of the recommended GOLD strategies for pharmacological treatment of COPD based on the A, B, C, and D groups. Here, our focus of 
this survey is to determine the degree of consensus in the Asian Pacific region's practice guidelines for COPD regarding the diagnosis and management of COPD.

\section{Estimated Prevalence}

The prevalence of COPD in the Asia-Pacific countries is estimated at $14.5 \%$ in Australia [4], 4.4\% to $16.7 \%$ in China [5-7], and 5.6\% in Indonesia [1]; the prevalence of Air Flow Limitation (FEV1/FVC $<70 \%$ ) was reported at $10.9 \%$ and COPD (after excluding asthmatics) was $8.6 \%$ in Japan [8], 13.4\% in Korea [9], 4.7\% in Malaysia [1], 5.4\% to $6.1 \%$ in Taiwan [1,10], 3.7\% to $6.8 \%$ in Thailand [11], 3.5\% to $20.8 \%$ in Philippines [1,12], and $6.7 \%$ in Vietnam [1], respectively (Table 1).

Table 1. Publication year of current and last version of Asia Pacific (APAC) guidelines, and COPD prevalence in the reviewed APAC countries.

\begin{tabular}{|c|c|c|c|c|c|c|c|c|c|c|}
\hline & Australia/New Zealand * & China & Indonesia & Japan & Korea & Malaysia & Taiwan & Thailand & Philippines & Vietnam \\
\hline Current version & 2020 & 2017 & 2011 & 2018 & 2018 & 2009 & 2020 & 2010 & 2009 & 2009 \\
\hline Last version & 2013 & 2007 & NA & 2009 & 2014 & 1998 & 2011 & NA & 2003 & 2009 \\
\hline Planned next version & NA & NA & NA & NA & NA & NA & 2023 & 2016 & NA & 2018 \\
\hline COPD prevalence & $14.5 \%$ & $4.4-16.7 \%$ & $5.6 \%$ & $8.6-10.9 \%$ & $13.4 \%$ & $4.7 \%$ & $5.4-6.1 \%$ & $3.7-6.8 \%$ & $3.5-20.8 \%$ & $6.7 \%$ \\
\hline
\end{tabular}

* Stepwise management table of COPD was published in 2017; Concise Guide for Primary Care (COPD-X plan) was published in 2017.

\section{Method}

A survey was conducted across country-level members of the Asia-Pacific Society of Respiratory (APSR) for collecting an updated version of COPD guidelines which were implemented in each country. The APSR sent a questionnaire to members, who were asked to provide the current local guideline and comparative review of the collected guidelines. Ten guidelines were reviewed, including those of Australia/New Zealand, China, Indonesia, Japan, Korea, Malaysia, Taiwan, Thailand, Philippines, and Vietnam, in either English or national language. The key disease management graphs, flowcharts, and algorithms were translated into English language for review. Detailed information was completely collected, including the definition, the approach to diagnosis, severity classification of staging, pharmacotherapy for stable COPD, and other recommendations. In the Asia-Pacific available COPD guidelines, Australia, Japan, Korea, Taiwan, and China have revised and updated guidelines during the period of 2013 to 2020 (Table 1). Guidelines in the other countries were not revised in the recent three years. We compared the similarities and differences between these guidelines.

The different methods used to estimate disease prevalence including expert opinion, patient-reported diagnosis, and symptom-based or spirometry-based methods may affect the results. In the People's Republic of China, COPD is one of the most common chronic diseases in the population older than 40 years of age, with a prevalence of $8.2 \%$ in 2007 and increased to $13.6 \%$ in 2015 using spirometry-based survey. [5,7] Comparatively higher prevalence with $13.7 \%$ to $13.4 \%$ was noted in Korea using spirometry-based survey $[9,13]$. Another study in the Asia-Pacific region, EPIC Asia population-based survey [1] based on face-to-face or fixed-line telephone interviews, revealed that the prevalence of COPD is between $6.2 \%$ and $19.1 \%$. Regarding the estimated prevalence rate of COPD in each country, there is no appropriate method to do this in current status.

\section{Results}

COPD diagnosis, classification, and treatment recommendation from Taiwan and China were similar to the GOLD guidelines. The degree of airflow limitation, assessment of COPD severity, management, and pharmacologic therapy of stable COPD were based on the GOLD principles. Australia, Japan, and Korea guidelines display some differences regarding classification and management strategy of stable COPD compared with the GOLD (Table 2). Besides, Taiwan guidelines have been written based on GRADE (Grading of Recommendations, Assessment, Development and Evaluations)'s recommen- 
dation, which is the most widely adopted tool for grading the quality of evidence and for making recommendations.

Table 2. Comparison of GOLD 2015 and APAC guidelines with current version updated after 2011.

\begin{tabular}{|c|c|c|c|c|c|}
\hline & \multicolumn{2}{|l|}{$\begin{array}{l}\text { Disease Classification and Management } \\
\text { Recommendation Same as GOLD }\end{array}$} & \multirow{2}{*}{$\begin{array}{l}\text { Major Difference in COPD } \\
\text { Diagnosis Classification } \\
\text { Typical symptoms and lung } \\
\text { function assessed in parallel for } \\
\text { COPD severity classification } \\
\text { FEV1 } 40 \%, 60 \% \text { and } 80 \% \\
\text { predicted as the cut points of } \\
\text { COPD severity } \\
\text { No specified cut points of } \\
\text { mMRC and CAT for } \\
\text { symptom evaluation }\end{array}$} & \multicolumn{2}{|r|}{$\begin{array}{l}\text { Major Difference in COPD } \\
\text { Treatment Recommendation }\end{array}$} \\
\hline Australia & No & $\begin{array}{l}(1) \\
(2)\end{array}$ & & (1) & $\begin{array}{l}\text { Stepwise management of } \\
\text { stable COPD; therapeutic } \\
\text { choices appropriately fully } \\
\text { aligned with disease severity. }\end{array}$ \\
\hline China & Yes & & & & \\
\hline Japan & No & $(2)$ & $\begin{array}{l}\text { Typical symptoms and lung } \\
\text { function assessed in parallel for } \\
\text { COPD severity classification } \\
\text { No specified cut points of } \\
\text { mMRC and CAT for } \\
\text { symptom evaluation }\end{array}$ & (1) & $\begin{array}{l}\text { Stepwise management of } \\
\text { stable COPD; therapeutic } \\
\text { choices not fully aligned } \\
\text { with disease severity. }\end{array}$ \\
\hline Korea & No & $\begin{array}{l}(1) \\
(2)\end{array}$ & $\begin{array}{l}\text { FEV1 } 60 \% \text { predicted as the cut } \\
\text { point of high- and low-risk class. } \\
\text { Combined GOLD C and GOLD } \\
\text { D into one group (Korean } \\
\text { group 'da') }\end{array}$ & $(1)$ & $\begin{array}{l}\text { Specified criteria, the } \\
\text { occurrence of exacerbation } \\
\text { or mMRC } \geq 2 \text { despite of } \\
\text { current treatment, for add } \\
\text { up treatment from first } \\
\text { therapeutic choice. } \\
\text { Mixed treatment } \\
\text { recommendation of GOLD } \\
C \text { and D for group 'da.' }\end{array}$ \\
\hline Taiwan & Yes & & & & \\
\hline
\end{tabular}

\subsection{Combined COPD Assessment}

The Korean COPD guideline categorizes severity into three groups, Group ga (GOLD Group A), Group na (GOLD Group B), and Group da (GOLD Group C and D) [13] (Figure 1). The spirometric cutoff point of FEV1 is $60 \%$ predicted to distinct Group ga, na from Group da. They further divide Group da into two groups with FEV1 < 60\% predicted, but $>=50 \%$ predicted, or FEV1 $<50 \%$ predicted. [14]. Assessment of symptoms and exacerbation is similar as described in GOLD. In Australia, COPD-X concise guide [15] for primary care categorizes the severity of COPD into mild (FEV1: 60-80\% of predicted), moderate (FEV1: $40-59 \%$ of predicted), and severe (FEV1: $<40 \%$ of predicted) accompanied with typical symptoms of varying degree of dyspnea, cough, and limitation of daily activity (Figure 2) [16]. The rationale was that regular treatment with inhaled corticosteroid (ICS) can improve symptoms, lung function, quality of life, and reduce the frequency of exacerbation for patients with FEV1 $<50 \%$ predicted and a history of frequent exacerbations, observed in several clinical studies [16-18]. 


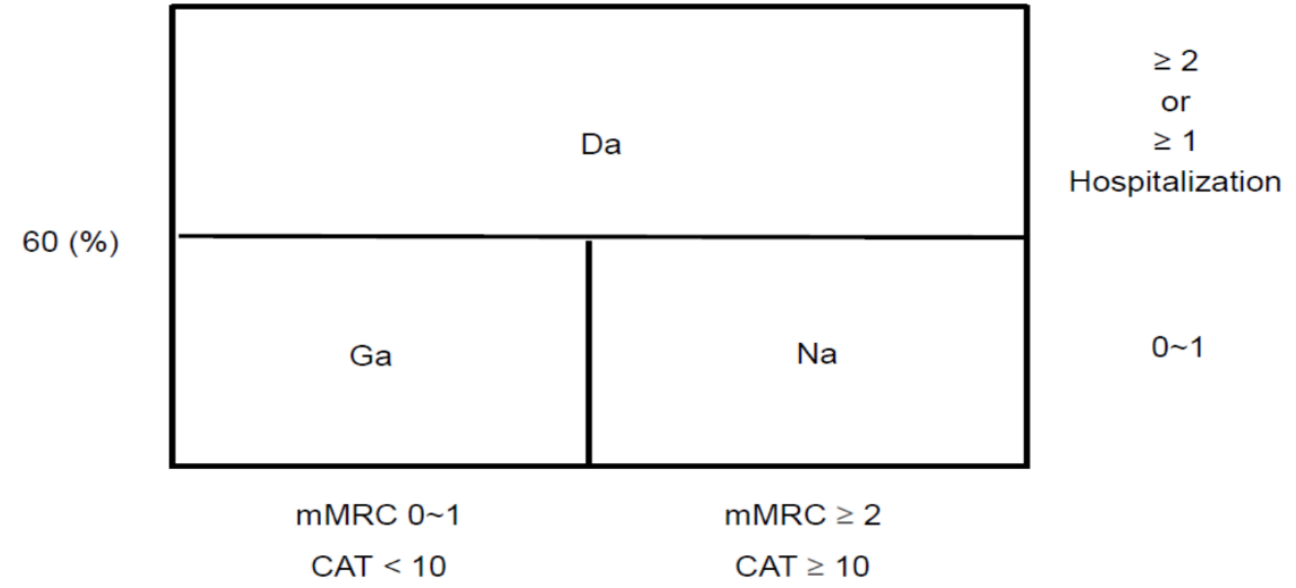

Figure 1. Korean COPD classification system and GOLD classification system.

\begin{tabular}{|c|c|c|c|}
\hline & MILD & MODERATE & SEVERE \\
\hline Typical Symptoms & $\begin{array}{l}\text { - few symptoms } \\
\text { - breathless on moderate } \\
\text { exertion } \\
\text { - recurrent chest infections } \\
\text { - little or no effect on daily } \\
\text { activities }\end{array}$ & $\begin{array}{l}\text { - increasing dyspnoea } \\
\text { - breathless walking on level ground } \\
\text { - increasing limitation of daily activities } \\
\text { - exacerbations requiring oral } \\
\text { corticosteroids and/or antibiotics }\end{array}$ & $\begin{array}{l}\text { - dyspnoea on minimal exertion } \\
\text { - daily activities severely curtailed } \\
\text { - experiencing regular sputum production } \\
\text { - chronic cough } \\
\text { - exacerbations of increasing frequency and } \\
\text { severity }\end{array}$ \\
\hline Lung Function & FEV1 $\approx 60 \sim 80 \%$ predicted & FEV $1 \approx 40 \sim 59 \%$ predicted & FEV $1<40 \%$ predicted \\
\hline Non-Pharmacological & \multicolumn{3}{|c|}{$\begin{array}{l}\text { RISK REDUCTION Check smoking status, support smoking cessation, recommend annual influenza and pneumococcal vaccine } \\
\text { according to immunization handbook }\end{array}$} \\
\hline Management of stable COPD & \multicolumn{3}{|c|}{$\begin{array}{l}\text { OPTIMISE FUNCTION Encourage physical activity, review nutrition, provide education, develop GP management plan and initiate } \\
\text { regular review }\end{array}$} \\
\hline $\begin{array}{l}\text { smoking patients to quit. } \\
\text { Encouraging physical activity }\end{array}$ & \multicolumn{3}{|c|}{ CONSIDER CO-MORBIDITIES especially osteoporosis, coronary disease, lung cancer, anxiety and depression } \\
\hline $\begin{array}{l}\text { and maintenance of a normal } \\
\text { weight range are also important. } \\
\text { Pulmonary rehabilitation is }\end{array}$ & \multicolumn{3}{|c|}{ REFER TO PULMONARY REHABILITATION and consider psychosocial needs, agree written action plan } \\
\hline $\begin{array}{r}\text { recommended in symptomatic } \\
\text { patients. }\end{array}$ & & & $\begin{array}{l}\text { Consider oxygen therapy, surgery, palliative } \\
\text { care and advanced care directives }\end{array}$ \\
\hline \multirow{2}{*}{$\begin{array}{r}\text { Pharmacological } \\
\text { Interventions }\end{array}$} & \multicolumn{3}{|c|}{ CHECK DEVICE USAGE AND ADHERENCE AT EACH VISIT- Up to $90 \%$ of patients don't use devices correctly } \\
\hline & \multicolumn{3}{|c|}{$\begin{array}{l}\text { SHORT-ACTING RELIEVER MEDICATION: Short-acting beta2-agonist (SABA) or short-acting muscarinic antagonist (SABA). } \\
\text { Refer to Table } 1 \text { overleaf. }\end{array}$} \\
\hline $\begin{array}{l}\text { treatment may be to treat } \\
\text { Symptoms (e.g. breathlessness) } \\
\text { or to prevent deterioration } \\
\text { (either by decreasing }\end{array}$ & \multicolumn{3}{|c|}{$\begin{array}{l}\text { SYMPTOM RELIEF: Long-acting muscarinic antagonist (LAMA) and/or long-acting beta2-agonist (LABA), } \\
\text { Refer to Table } 1 \text { overleaf. These medicines may also help to prevent exacerbations. }{ }^{*} \text { SEE PRECAUTIONS }{ }^{1 \sim 3 * *}\end{array}$} \\
\hline $\begin{array}{l}\text { exacerbations or by reducing } \\
\text { decline in quality or life) or } \\
\text { both. A stepwise approach is } \\
\text { recommended, irrespective of }\end{array}$ & & \multicolumn{2}{|c|}{$\begin{array}{l}\text { EXACERBATION PREVENTION: When FEV } 1<50 \% \text { predicted AND } 2 \text { or } \\
\text { more exacerbations in the previous } 12 \text { months, consider commencing inhaled } \\
\text { corticosteroid (ICS)/LABA combination therapy. }{ }^{* x} \text { SEE PRECAUTION } \text { S }^{* * *}\end{array}$} \\
\hline control has been achieved. & & & Consider low dose theophylline \\
\hline
\end{tabular}

Based on COPD-X Plan: Australian and new Zeeland Guidelines for the Management of COPD; Australian Therapeutic Guidelines

Figure 2. Stepwise management of stable COPD guidelines in Australia and New Zealand. 


\subsection{Pharmacologic Management of Stable Disease}

In the GOLD guideline, the initial pharmacological management of COPD is according to patient group which has different recommended treatments. In the guidelines of Australia, Japan, and Korea (Figure 2 [15], Figure 3 [19], and Figure 4 [14]), a stepwise approach of optimized pharmacotherapy for stable COPD is used which recommends a gradual increase of bronchodilators, inhaled corticosteroids, or other drugs based on a comprehensive evaluation of symptoms, airflow obstruction, and exacerbation. In Japan's 2018 guideline, ICS positioning for COPD treatment had been revised from the previous criteria of FEV $1<50 \%$ of predicted, frequent exacerbation, and concomitant asthma to only the concomitant asthma (ACO) criterion.

\subsection{Non-Pharmacologic Management}

Most guidelines had emphasized the importance of pulmonary rehabilitation, longterm oxygen therapy, and self-management plan including smoking cessation and vaccination. Particularly, Japan's guideline (fifth edition) discussed the nutrition management including nutritional impairment, evaluation, therapy, and diet education [19]. COPD patients whose BMI is less than $90 \%$ are suspected to have a nutrition disorder and nutrition therapy may be indicated. Nutritionists, physician, and nurses should form a team to provide nutritional guidance.

Mild $\quad$ Severe

Disease Severity

\begin{tabular}{|l|}
\hline \\
dyspnea/exacerbation (severity/frequency) \\
FEV 1 /exercise tolerance/physical activity \\
\hline
\end{tabular}

Add ICS (Concomitant Asthma)

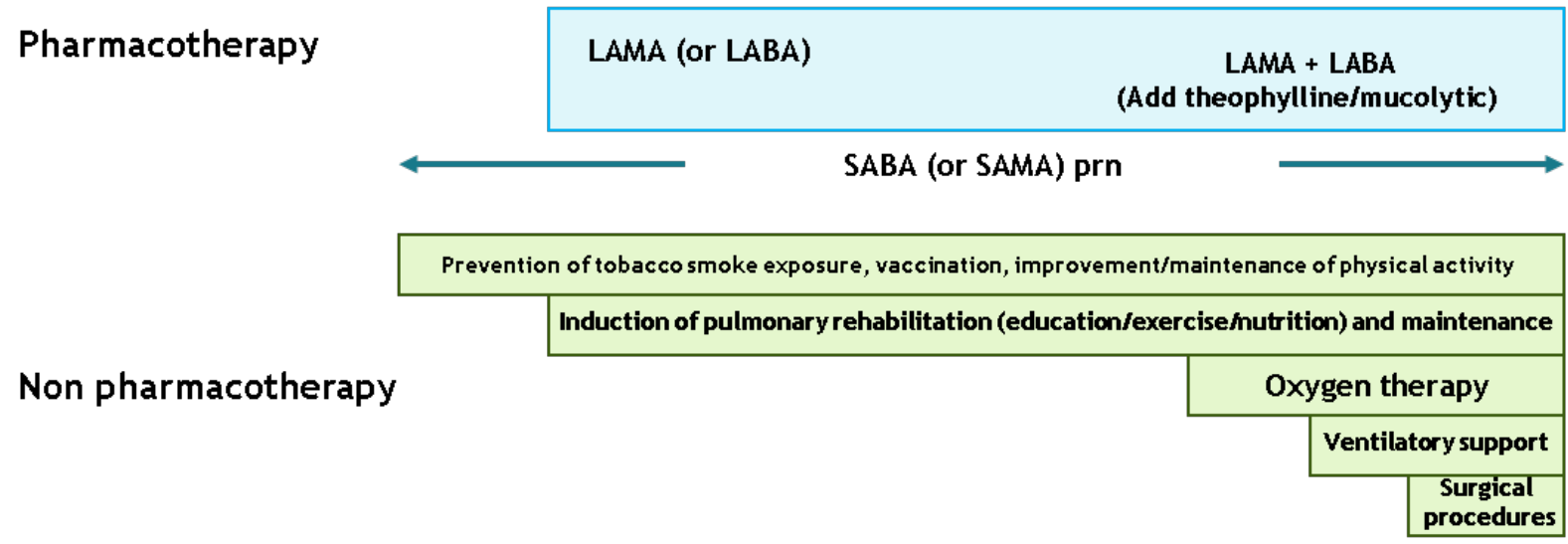

- The severity of COPD should be comprehensively assessed on the basis of not only the degree of decrease of FEV (clinical stage), but also the degree of impairment of exercise tolerance/physical activity, intensity of dyspnea, and frequency/severity of exacerbation.

- $\mathrm{FEV}_{1}$, exercise tolerance, and physical activity usually decrease in accordance with increased severity of COPD, and increased dyspnea and more frequent exacerbation are noted. However, when there is a gap between the degree of FEV and other factors, attention should be paid to presence of comorbidities such as cardiac diseases.

- Treatment with medication and non-medication therapies should be given. When medication with a single drug is not sufficiently successful, LAMA and LABA should be used in combination (use of LAMA/LABA combinations is also allowed).

- ICS should be used in cases with possible concomitant asthmatic conditions. LABA/ICS combinations are also allowed.

Figure 3. Stepwise approach recommended by the fifth edition of Japanese Respiratory Society COPD guidelines. 


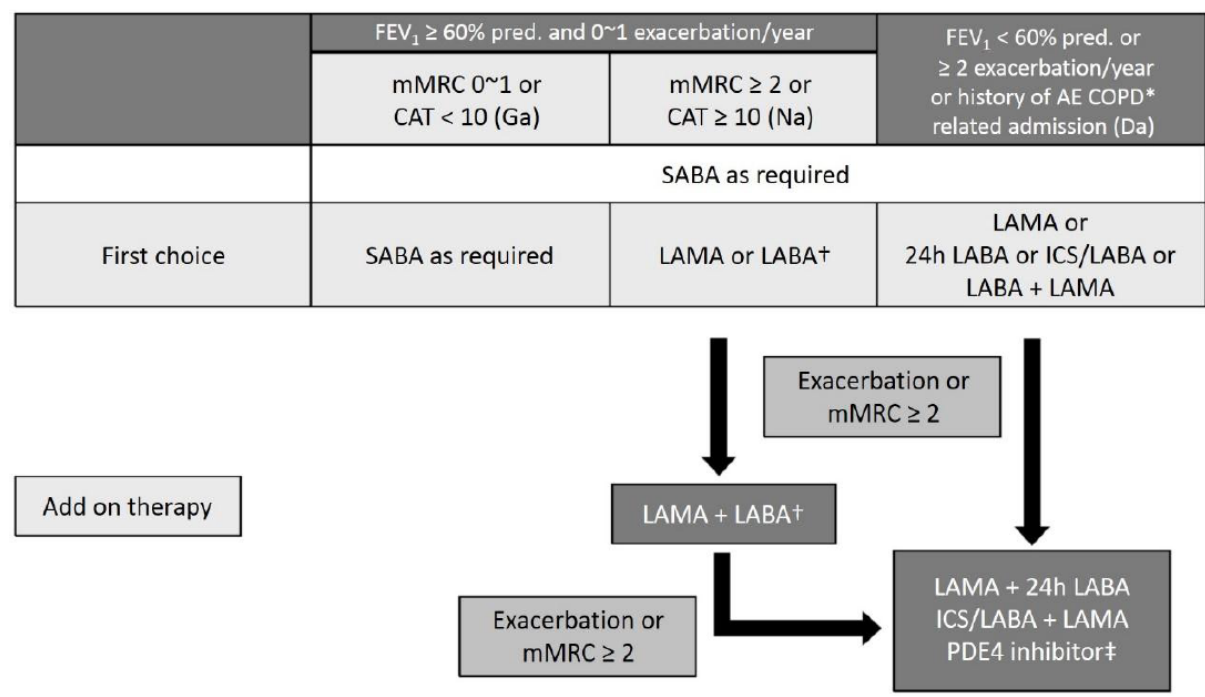

*AE COPD: Acute exacerbation of COPD

+Including 24h LABA

¥FEV1 $<50 \%$, chronic bronchitis, and history of exacerbation

SABA: Short Acting Beta Agonist

LABA: Long Acting Beta Agonist

LAMA: Long Acting Muscarinic antagonist

Figure 4. Algorithm of pharmacologic treatment in patients with stable COPD in Korea.

\subsection{Coexisting Asthma and COPD}

Coexisting asthma and COPD are only defined and described in Australia and Japan guidelines. This Australia guideline recommends that an FEV1 increase over 12\% and $200 \mathrm{~mL}$ constitutes a positive bronchodilator response. An FEV1 increase $>400 \mathrm{~mL}$ strongly suggests underlying asthma or coexisting asthma and COPD diagnosis. Besides, the diagnosis of asthma-COPD overlap (ACO) has both characteristics of COPD and asthma (Figure 5).

\subsection{End-of-Life ISSUES}

GOLD 2013, for the first time, proposed that palliative care may be applied in advanced severe COPD patients. Among these guidelines in the Asia-Pacific region, Taiwan, Japan, China [20], and Australia [15] may already have their policies about end-of-life care. Improving quality of life, optimizing function, helping with decision- making about endof-life care, and providing emotional and spiritual support to patients and family are the main goals. In Taiwan, the National Health Insurance Administration Ministry of Health and Welfare had programmed hospice-care plans in 2011 and provided in-hospital critical care facilities for patients with advanced diseases and poor response to regular treatments instead of home or hospice ward care. 


\begin{tabular}{|c|c|}
\hline \multicolumn{2}{|c|}{ Fundamentals } \\
\hline \multicolumn{2}{|c|}{40 years of age or older, Chronic airway inflammation: post-bronchodilator $\mathrm{FEV}_{1} / \mathrm{FVC}<70 \%$} \\
\hline [Characteristics of COPD]One of item (1), (2), and (3) & $\begin{array}{l}\text { [Characteristics of Asthma]Two of item (1), (2), and (3) / One } \\
\text { of item (1), (2), and (3) with two or more of item (4) }\end{array}$ \\
\hline $\begin{array}{l}\text { (1) At least } 10 \text { pack-years of tobacco smoking or equivalent air } \\
\text { pollution exposure }\end{array}$ & $\begin{array}{l}\text { (1) Variable(over the course of one day, from day to day, } \\
\text { seasonal) or paroxysmal respiratory symptoms (cough, } \\
\text { sputum, and dyspnea) }\end{array}$ \\
\hline \multirow{2}{*}{$\begin{array}{l}\text { (2) Present low attenuation area denoting emphysematous } \\
\text { change on chest CT scan }\end{array}$} & History of asthma before 40 years of age \\
\hline & (3) $\quad \mathrm{FeNO}>35 \mathrm{ppb}$ \\
\hline $\begin{array}{l}\text { (3) Abnormal pulmonary diffusingcapacity }\left(\% \mathrm{D}_{\mathrm{LCO}}<80 \%\right. \\
\left.\text { or } \% \mathrm{D}_{\mathrm{LCO}} / \mathrm{V}_{\mathrm{A}}<80 \%\right)\end{array}$ & $\begin{array}{l}\text { (4)-1. Comorbidity of perennial allergic rhinitis } \\
\text {-2. Bronchodilator reversibility (increase in } \mathrm{FEV}_{1}>12 \% \text { and }> \\
200 \mathrm{~mL} \text { from baseline) } \\
\text {-3. Peripheral blood eosinophil counts of }>5 \% \text { or } 300 / \mu \mathrm{L} \\
\text {-4. Higher IgE (total IgE or specific IgE sensitized to } \\
\text { perennial inhalation antigen) }\end{array}$ \\
\hline
\end{tabular}

1. The diagnostic criteria of ACO are having both characteristics of COPD and asthma.

(Characteristics of COPD; One of item (1), (2), and (3) of [Characteristics of COPD.] Characteristics of asthma; Two of item (1), (2), and (3) of [characteristics of asthma] / one of items (1), (2), (3) with two or more of item (4) of [characteristics of asthma.])

2. Diagnosed as COPD when the patient match only characteristics of COPD. And diagnosed as asthma with the remodeling when the patient match only characteristics of asthma.

3. If you can not determine the characteristics of asthma when diagnosing $A C O$, it is important to observe the progress of the presence or absence of features of asthma.

4. Perennial inhalation antigens are house dust, mite, molds, animal scales, feathers, etc. Seasonal inhalation antigens are pollen of tree, plant, and weed, etc.

Figure 5. Diagnostic criteria of asthma-COPD overlap in Japanese ACO guideline 2018.

\section{Discussion}

There are several studies evaluating and validating the new GOLD assessment system; however, uneven distribution of COPD patients and limited data on the clinical outcomes are noticed under these combined assessments. [21-24] The degree of the COPD Assessment Test (CAT) score of $\geq 10$ might not be equivalent to that of the mMRC score of $\geq 2$ for categorizing patients' symptoms. [25-28] Neither the 2007 GOLD nor the 2011 classification scheme has sufficient discriminatory power to be used clinically for risk classification to predict total mortality at the individual level. [29] Accordingly, some countries have developed COPD guidelines to build up appropriate strategies for diagnosis, assessment, pharmacotherapy, and prediction of acute exacerbation and mortality based on evidence and real-world clinical practice.

The Korean and Australia guidelines stratified the lung function severity and exacerbation risk with FEV1 $<60 \%$ or $\geq 60 \%$ of predicted value. From the validation study in Korea, it was found that there were many patients (15.3\% to $16 \%)$ who experienced exacerbation with FEV1 between $50 \%$ and $60 \%$ of predicted value. [14] The cutoff point of an FEV1 50\% predicted does not address the heterogeneity in the GOLD Stage II (50\%-80\% predicted). Patients with limited airflow around FEV1 $50 \%$ to $60 \%$ predicted had a more rapid decline in lung function than patients with FEV1 $<50 \%$ in the TORCH study $[30,31]$. A recent study showed that parameters related to volume, diffusing capacity, and reactance showed break-points around 65\% of FEV1 which may have an impact on patients' management plan.

The strategy for stable COPD management was based on lung function severity before GOLD 2011. A refinement of the ABCD assessment tool had been separated from spirometric grade from "ABCD" groups in GOLD 2020. A stepwise approach policy is currently presented in the Japan and Australia guidelines. The management strategy is similar in the Korea and GOLD guidelines including for symptoms severity and exacerbation frequency. Moreover, a phenotype-guided treatment policy has been shown in the Spanish and Czech guidelines. [32,33] Which strategies are optimal in clinical practice guidelines for COPD management? There were several strategies including lung function-guided, stepwise approach-guided, GOLD A-D-guided, and phenotype-guided strategies. The optimal treatment of COPD patients requires an individualized, multidisciplinary approach to the 
lung function severity, patient's symptoms, clinical phenotypes, biomarkers, comorbidity evaluation, and needs.

The treatment of patients with COPD in a more personalized way must address diverse aspects not only related with the disease, but also with its comorbidities, and current schemes do not offer such personalized medical treatment. Comorbidity evaluation and management were all mentioned in each Asia country CPG. In the JRS guideline 119], the comorbidities included systemic inflammation, osteoporosis, musculoskeletal defect, cardiovascular disorders, gastro-intestinal dysfunction, depression, metabolic disorders, and obstructive sleep apnea. Additionally, the variability of the clinical presentation interacts with comorbidities to form a complex clinical scenario for clinicians. Different comorbidities have different evaluation and management policies. Consequently, the CPG or consensus should be reached over a practical approach for combining comorbidities and disease presentation markers in the therapeutic algorithm, in order to improve the quality of clinical care.

In a previous study, the increased total health expenditure was shown as share GDP $\geq 7 \%$ in Korea, Japan, and Australia in 2007. [34] In Japan, major reforms are needed to reduce waste and enhance cost-effectiveness. Moreover, a national system to accredit training programs, including for general practice, has been introduced. [35] The challenges of the healthcare system in Korea include over-consumption and excessively high frequency of specialist consultation, which are major problems for the medical system. The government and the primary care group seek to strengthen primary care, but this is opposed by the medical society governed by the specialist group. [35] In Australia, some provider payment methods were performed such as case payment, diagnostic-related groups, etc. [34]. We think that guideline differences are driven by the disparities in diagnosis modalities or by the treatment variations in different healthcare systems and the socioeconomic burden in each country.

Additionally, diagnosis tools and management of COPD were among the lower guideline-recommended levels in most of the regions investigated among primary care physicians or general practitioners (GPs). [36] The survey demonstrated that the GPs' understanding of COPD was variable and large numbers of GPs have very limited knowledge of COPD and its management in Asia countries. The percentage for COPD management by guideline is as follows: Australia $64 \%$, Japan $74 \%$, Korea $54 \%$, and Taiwan $70 \%$. In China, only $50 \%$ of patients with COPD have ever had spirometry tests in tertiary hospitals, and only $18 \%$ had in primary or secondary hospitals. [37] Therefore, from the education system, clinical practice, and medical impact, there appears to be an optimal strategy developed to simplify the guidelines for daily practice in each country.

Research evidence has raised concerns that hospital death may be preceded by potentially burdensome and inappropriate hospital admission and aggressive treatments shortly before death, which could be a threat to better end-of-life care and death. [38-41] On the other hand, enabling people to have end-of-life care at home compared with end-of-life care in hospital may incur a potential cost saving. [42,43] The concepts of palliative and hospice care should be established gradually in regards to diseases with an advanced stage.

\section{APSR Recommendations for COPD Diagnosis and Treatment}

1. COPD is characterized by persistent respiratory symptoms and airflow limitation. Spirometry is required to make the diagnosis.

2. The severity of COPD should be comprehensively assessed on the basis of the degree of obstruction severity (FEV1, GOLD stage), impairment of exercise tolerance/physical activity, intensity of dyspnea, and frequency/ severity of exacerbation.

3. The goal of pharmacological treatment should be to treat the symptoms (e.g., breathlessness) or to prevent deterioration (either by decreasing exacerbations or by reducing the decline in lung function and quality of life) or both. A stepwise approach is recommended, irrespective of disease severity, until adequate control has been achieved. 
4. Management of non-pharmacological strategies for stable COPD should center around supporting smoking patients to quit. Encouraging physical activity and maintenance of a normal weight range are also important. Pulmonary rehabilitation is recommended in all symptomatic patients.

5. Stepwise management of optimized pharmacotherapy for stable COPD which recommends gradual increase of bronchodilators, inhaled corticosteroids, or other drugs based on clinical symptoms, airflow obstruction severity, and exacerbation history.

6. ICS should be used in cases with concomitant asthmatic conditions and/or 2 or more exacerbations in the previous 12 months. LABA/ICS combinations are also allowed.

7. In the end-of-life care, improving quality of life and providing emotional and spiritual support to COPD patients and their family are the main goals.

\section{Conclusions}

This is the first report to summarize the similarities and differences among the COPD guidelines across the Asia-Pacific region. The guideline developed in each country would be based on clinical evidence, experts' consensus, healthcare insurance, reality of clinical practice, and the best interests of patients. We hope, through collaboration of research, that the guidelines will evolve positively and that differences or gaps will diminish with time.

Author Contributions: S.-L.C. and C.-H.L.; methodology, validation, and formal analysis; S.-L.C.; writing-original draft preparation, S.-L.C.; writing-review and editing, C.-H.L. Both authors have read and agreed to the published version of the manuscript.

Funding: This research received no external funding.

Institutional Review Board Statement: Not applicable.

Informed Consent Statement: Not applicable.

Data Availability Statement: Not applicable.

Acknowledgments: Thanks to the professors for finishing this work including: Kazuto Matsunaga (Japan); Chin Kook Rhee (Korea); Diahn-Warng Perng (Taiwan).

Conflicts of Interest: The authors declare no conflict of interest.

\section{References}

1. Lim, S.; Lam, D.C.-L.; Muttalif, A.R.; Yunus, F.; Wongtim, S.; Lan, L.T.T.; Shetty, V.; Chu, R.; Zheng, J.; Perng, D.-W.; et al. Impact of chronic obstructive pulmonary disease (COPD) in the Asia-Pacific region: The EPIC Asia population-based survey. Asia Pac. Fam. Med. 2015, 14, 1-11. [CrossRef]

2. Vogelmeier, C.F.; Criner, G.J.; Martinez, F.J.; Anzueto, A.; Barnes, P.J.; Bourbeau, J.; Celli, B.R.; Chen, R.; Decramer, M.; Fabbri, L.M.; et al. Global strategy for the diagnosis, management, and prevention of chronic obstructive pulmonary disease: GOLD executive summary. Am. J. Respir. Crit. Care Med. 2017, 195, 557-582. [CrossRef]

3. Global Initiative for Chronic Obstructive Lung Disease (GOLD). Global Strategy for the Diagnosis, Management and Prevention of Chronic Obstructive Pulmonary Disease. GOLD. 2015. Available online: http:/ /www.goldcopd.org/uploads/users/files / GOLD_Report_2015_Feb18.pdf. (accessed on 27 March 2015).

4. Cooksley, N.A.; Atkinson, D.; Marks, G.B.; Toelle, B.G.; Reeve, D.; Johns, D.P.; Abramson, M.; Burton, D.L.; James, A.L.; WoodBaker, R.; et al. Prevalence of airflow obstruction and reduced forced vital capacity in an Aboriginal Australian population: The cross-sectional BOLD study. Respirology 2015, 20, 766-774. [CrossRef] [PubMed]

5. Zhong, N.; Wang, C.; Yao, W.; Chen, P.; Kang, J.; Huang, S.; Wang, C.; Ni, D.; Zhou, Y.; Liu, S.; et al. Prevalence of chronic obstructive pulmonary disease in China: A large, population-based survey. Am. J. Respir. Crit Care Med. 2007, 176, 753-760. [CrossRef] [PubMed]

6. Fang, X.; Wang, X.; Bai, C. COPD in China: The burden and importance of proper management. Chest 2011, 139, 920-929. [CrossRef] [PubMed]

7. Fang, L.; Gao, P.; Bao, H.; Tang, X.; Wang, B.; Feng, Y.; Cong, S.; Juan, J.; Fan, J.; Lu, K.; et al. Chronic obstructive pulmonary disease in China: A nationwide prevalence study. Lancet Respir. Med. 2018, 6, 421-430. [CrossRef]

8. Fukuchi, Y.; Nishimura, M.; Ichinose, M.; Adachi, M.; Nagai, A.; Kuriyama, T.; Takahashi, K.; Nishimura, K.; Ishioka, S.; Aizawa, H.; et al. COPD in Japan: The Nippon COPD Epidemiology study. Respirology 2004, 9, 458-465. [CrossRef] [PubMed]

9. Hwang, Y.I.; Park, Y.B.; Yoo, K.H. Recent Trends in the Prevalence of Chronic Obstructive Pulmonary Disease in Korea. Tuberc. Respir. Dis. 2017, 80, 226-229. [CrossRef] 
10. Yu, C.-J.; Cheng, S.-L.; Chan, M.-C.; Wang, C.-C.; Lin, C.-H.; Wang, H.-C.; Hsu, J.-Y.; Hang, L.-W.; Chang, C.-J.; Perng, S.D.-W. COPD in Taiwan: A National Epidemiology Survey. Int. J. Chronic Obstr. Pulm. Dis. 2015, 10, 2459-2467. [CrossRef]

11. Pothirat, C.; Chaiwong, W.; Phetsuk, N.; Pisalthanapuna, S.; Chetsadaphan, N.; Inchai, J. A comparative study of COPD burden between urban vs rural communities in northern Thailand. Int. J. Chronic Obstr. Pulm. Dis. 2015, 10, 1035-1042. [CrossRef]

12. Idolor, L.F.; Guia, T.S.D.E.; Francisco, N.A.; Roa, C.C.; Ayuyao, F.G.; Tady, C.Z.; Tan, D.T.; Banal-Yang, S.; Balanag, V.M., Jr.; Reyes, M.T.N.; et al. Burden of obstructive lung disease in a rural setting in the philippines. Respirology 2011, 16, 1111-1118. [CrossRef]

13. Park, H.; Jung, S.Y.; Lee, K.; Bae, W.K.; Lee, K.; Han, J.-S.; Kim, S.; Choo, S.; Jeong, J.-M.; Kim, H.-R.; et al. Prevalence of Chronic Obstructive Lung Disease in Korea Using Data from the Fifth Korea National Health and Nutrition Examination Survey. Korean J. Fam. Med. 2015, 36, 128-134. [CrossRef] [PubMed]

14. Park, Y.-B.; Rhee, C.K.; Yoon, H.K.; Oh, Y.-M.; Lim, S.Y.; Lee, J.H.; Yoo, K.-H.; Ahn, J.H. on behalf of the Committee of the Korean COPD Guideline 2018 Revised (2018) COPD Clinical Practice Guideline of the Korean Academy of Tuberculosis and Respiratory Disease: A Summary. Tuberc. Respir. Dis. 2018, 81, 261-273. [CrossRef]

15. Yang, I.A.; Dabscheck, E.; Johnson George, J.; Jenkins, S.; Christine McDonald, A.M.; McDonald, V.; Smith, B.; Zwar, N.; Brown, J.L.; O'Brien, M.; et al. The COPD-X Plan: Australian and New Zealand Guidelines for the management of Chronic Obstructive Pulmonary Disease 2020. In COPD-X Guidelines-Version 2.62 (October 2020); Lung Foundation Australia: Milton, Australia, 2020.

16. Jung, K.S.; Park, H.Y.; Park, S.Y.; Kim, S.K.; Kim, Y.-K.; Shim, J.-J.; Moon, H.S.; Lee, K.H.; Yoo, J.-H.; Lee, S.D. Comparison of tiotropium plus fluticasone propionate/salmeterol with tiotropium in COPD: A randomized controlled study. Respir. Med. 2012, 106, 382-389. [CrossRef] [PubMed]

17. Calverley, P.; Pauwels, R.; Vestbo, J.; Jones, P.; Pride, N.; Gulsvik, A.; Anderson, J.; Maden, C.; TRial of Inhaled STeroids and Long-Acting beta2 Agonists Study Group. Combined salmeterol and fluticasone in the treatment of chronic obstructive pulmonary disease: A randomised controlled trial. Lancet 2003, 361, 449-456. [CrossRef]

18. Calverley, P.M.; Anderson, J.A.; Celli, B.R.; Ferguson, G.T.; Jenkins, C.R.; Jones, P.W.; Yates, J.C.; Vestbo, J. Salmeterol and Fluticasone Propionate and Survival in Chronic Obstructive Pulmonary Disease. N. Engl. J. Med. 2007, 356, 775-789. [CrossRef]

19. Japanese Respiratory Society. Guidelines for the Diagnosis and Treatment of COPD, 5th ed.; Japanese Respiratory Society: Tokyo, Japan, 2018; Available online: https:/ / www.jrs.or.jp/modules/guidelines/index.php?content_id=1 (accessed on 19 April 2013)

20. Zhang, J.; Cai, B.-Q.; Cai, S.-X.; Chen, R.-C.; Cui, L.-Y.; Feng, Y.-L.; Gu, Y.-T.; Huang, S.-G.; Liu, R.-Y.; Liu, G.-N.; et al. Expert consensus on acute exacerbation of chronic obstructive pulmonary disease in the People's Republic of China. Int. J. Chronic Obstr. Pulm. Dis. 2014, 9, 381-395. [CrossRef]

21. Han, M.K.; Müllerová, H.; Curran-Everett, D.; Dransfield, M.T.; Washko, G.R.; Regan, E.A.; Bowler, R.P.; Beaty, T.H.; Hokanson, J.E.; Lynch, D.A.; et al. GOLD 2011 disease severity classification in COPDGene: A prospective cohort study. Lancet Respir. Med. 2013, 1, 43-50. [CrossRef]

22. Lange, P.; Marott, J.L.; Vestbo, J.; Olsen, K.R.; Ingebrigtsen, T.S.; Dahl, M.; Nordestgaard, B.G. Prediction of the clinical course of chronic obstructive pul $\neg$ monary disease, using the new GOLD classification: A study of the gen $\neg$ eral population. Am. J. Respir. Crit. Care Med. 2012, 186, 975-981. [CrossRef]

23. Soriano, J.B.; Alfageme, I.; Almagro, P.; Casanova, C.; Esteban, C.; Soler-Cataluña, J.J.; De Torres, J.P.; Martínez-Camblor, P.; Miravitlles, M.; Celli, B.R.; et al. Distribution and Prognostic Validity of the New Global Initiative for Chronic Obstructive Lung Disease Grading Classification. Chest 2013, 143, 694-702. [CrossRef]

24. Johannessen, A.; Nilsen, R.M.; Storebø, M.; Gulsvik, A.; Eagan, T.; Bakke, P. Comparison of 2011 and 2007 Global Initiative for Chronic Obstructive Lung Disease Guidelines for Predicting Mortality and Hospitalization. Am. J. Respir. Crit. Care Med. 2013, 188, 51-59. [CrossRef] [PubMed]

25. Jones, P.W.; Adamek, L.; Nadeau, G.; Banik, N. Comparisons of health status scores with MRC grades in COPD: Implications for the GOLD 2011 classification. Eur. Respir. J. 2013, 42, 647-654. [CrossRef] [PubMed]

26. Kim, S.; Oh, J.; Kim, Y.-I.; Ban, H.-J.; Kwon, Y.-S.; Oh, I.-J.; Kim, K.-S.; Kim, Y.-C.; Lim, S.-C. Differences in classification of COPD group using COPD assessment test (CAT) or modified Medical Research Council (mMRC) dyspnea scores: A cross-sectional analyses. BMC Pulm. Med. 2013, 13, 35. [CrossRef]

27. Zogg, S.; Dürr, S.; Miedinger, D.; Steveling, E.H.; Maier, S.; Leuppi, J.D. Differences in classification of COPD patients into risk groups A-D: A cross-sectional study. BMC Res. Notes 2014, 7, 562. [CrossRef] [PubMed]

28. Rhee, C.K.; Kim, J.W.; Hwang, Y.I.; Lee, J.H.; Jung, K.-S.; Lee, M.G.; Yoo, K.H.; Lee, S.H.; Shin, K.-C.; Yoon, H.K. Discrepancies between modified Medical Research Council dyspnea score and COPD assessment test score in patients with COPD. Int. J. Chronic Obstr. Pulm. Dis. 2015, 10, 1623-1631. [CrossRef]

29. Soriano, J.B.; Lamprecht, B.; Ramírez, A.S.; Martinez-Camblor, P.; Kaiser, B.; Alfageme, I.; Almagro, P.; Casanova, C.; Esteban, C.; Soler-Cataluña, J.J.; et al. Mortality prediction in chronic obstructive pulmonary disease comparing the GOLD 2007 and 2011 staging systems: A pooled analysis of individual patient data. Lancet Respir. Med. 2015, 3, 443-450. [CrossRef]

30. Celli, B.R.; Thomas, N.E.; Anderson, J.A.; Ferguson, G.T.; Jenkins, C.R.; Jones, P.W.; Vestbo, J.; Knobil, K.; Yates, J.C.; Calverle, P.M.A. Effect of pharmacotherapy on rate of decline of lung function in chronic obstructive pulmonary disease: Results from the TORCH study. Am. J. Respir. Crit Care Med. 2008, 178, 332-338. [CrossRef] [PubMed]

31. Jenkins, C.R.; Jones, P.W.; Calverley, P.M.A.; Celli, B.; Anderson, J.A.; Ferguson, G.T.; Yates, J.C.; Willits, L.R.; Vestbo, J. Efficacy of salmeterol/fluticasone propionate by GOLD stage of chronic obstructive pulmonary disease: Analysis from the randomised, placebo-controlled TORCH study. Respir. Res. 2009, 10, 59. [CrossRef] [PubMed] 
32. Koblizek, V.; Chlumsky, J.; Zindr, V.; Neumannova, K.; Zatloukal, J.; Zak, J.; Sedlák, V.; Kocianova, J.; Zatloukal, J.; Hejduk, K.; et al. Chronic Obstructive Pulmonary Disease: Official diagnosis and treatment guidelines of the Czech Pneumological and Phthisiological Society; a novel phenotypic approach to COPD with patient-oriented care. Biomed. Pap. 2013, 157, 189-201. [CrossRef] [PubMed]

33. Miravitlles, M.; Soler-Cataluña, J.J.; Calle, M.; Molina, J.; Almagro, P.; Quintano, J.A.; Riesco, J.A.; Trigueros, J.A.; Piñera, P.; Simón, A.; et al. Spanish Guideline for COPD (GesEPOC). Update 2014. Arch. Bronconeumol. 2014, 50 (Suppl. 1), 1-16. [CrossRef]

34. WHO. Health Financing Strategy for Asia Pacific Region (2010-2015); WHO: Geneva, Switzerland, 2009; NLM Classification: WA 525; ISBN 978-92-9061-458-6.

35. Van Weel, C.; Kassai, R.; Tsoi, G.W.; Hwang, S.-J.; Cho, K.; Wong, S.Y.-S.; Phui-Nah, C.; Jiang, S.; Ii, M.; Goodyear-Smith, F. Evolving health policy for primary care in the Asia Pacific region. Br. J. Gen. Pract. 2016, 66, e451-e453. [CrossRef]

36. Aisanov, Z.; Bai, C.; Bauerle, O.; Colodenco, F.D.; Feldman, C.; Hashimoto, S.; Jardim, J.; Lai, C.K.W.; Laniado-Laborin, R.; Nadeau, G.; et al. Primary care physician perceptions on the diagnosis and management of chronic obstructive pulmonary disease in diverse regions of the world. Int. J. Chronic Obstr. Pulm. Dis. 2012, 7, 271-282. [CrossRef]

37. Shen, N.; He, B. Is the new GOLD classification applicable in China? Lancet Glob. Health 2013, 1, e247-e248. [CrossRef]

38. Teno, J.M.; Gozalo, P.L.; Bynum, J.P.W.; Leland, N.E.; Miller, S.C.; Morden, N.E.; Scupp, T.; Goodman, D.C.; Mor, V. Change in end-of-life care for Medicare beneficiaries: Site of death, place of care, and health care transitions in 2000, 2005, and 2009. JAMA 2013, 309, 470-477. [CrossRef] [PubMed]

39. Block, L.V.D.; Deschepper, R.; Drieskens, K.; Bauwens, S.; Bilsen, J.; Bossuyt, N.; Deliens, L. Hospitalisations at the end of life: Using a sentinel surveillance network to study hospital use and associated patient, disease and healthcare factors. BMC Health Serv. Res. 2007, 7, 69. [CrossRef]

40. Willard, C.; Luker, K. Challenges to end of life care in the acute hospital setting. Palliat. Med. 2006, 20, 611-615. [CrossRef] [PubMed]

41. Wright, A.A.; Keating, N.L.; Balboni, T.A.; Matulonis, U.A.; Block, S.D.; Prigerson, H.G. Place of Death: Correlations With Quality of Life of Patients With Cancer and Predictors of Bereaved Caregivers' Mental Health. J. Clin. Oncol. 2010, 28, $4457-4464$. [CrossRef]

42. Hatziandreu, E.; Archontakis, F.; Daly, A. The Potential Cost Savings of Greater Use of Home- and Hospice- Based End of Life Care in England. 2008. Available online: http:/ / www.rand.org/pubs/technical_reports/TR642.html (accessed on 25 January 2014).

43. Marie Curie Cancer Care. Understanding the Cost of End of Life Care in Different Settings. 2012. Available online: https://www.mariecurie.org.uk/globalassets/media/documents/commissioning-our-services/publications/understandingcost-end-life-care-different-settingspdf (accessed on 25 January 2014). 